\title{
Innovative Enterprise Information Systems: An Imperative for Public Sector Organisations of the $90 \mathrm{~s}$.
}

\author{
Helen Hasan \\ Department of Business Systems \\ University of Wollongong \\ Wollongong 2522 \\ Australia \\ Phone: 6142213757 \\ Fax: 6142214474 \\ Email: h.hasan@uow.edu.au
}

\begin{abstract}
Public Sector organisations have urgent and often complex information needs but, with limited funding, may not be in a position to build expensive computerised systems. To solve this problem, organisations must be innovative in their use of IT to create effective Enterprise Information Systems. This paper describes some Executive Information Systems projects which provide insight into how this can be done, by adopting methods that allow innovation in the use of the myriad of IT tools and techniques that are now available.
\end{abstract}

Keywords
Innovation, Enterprise Information Systems, Executive Information Systems, Public Sector.

\section{INTRODUCTION}

"Information" can be an organisation's most important resource but the acquisition of the right "Information Technology" (IT) is a critical strategic issue and is often surrounded by confusion. The confusion begins with the term "IT" itself, which is commonly used in an organisation to denote all computer hardware and software whether or not the "technology" is specifically related to "information". Traditionally organisations have departments responsible for this area, variously called IT, DP (Data Processing) or IS (Information Systems). There may also be groups distributed throughout the organisation with responsibility for other areas such as Management Information (MIS). The concepts of IS and MIS are inextricable linked to the development of computer applications and the terms may often be used for applications that process very little actual "information". It is time for organisations to re-assess both their management information needs and the information systems to provide it.

The theme of this paper has emerged from 5 years of research by the author into Executive Information Systems (EIS) in Public Sector Organisations. Lessons learnt from several 
longitudinal case studies of ongoing EIS projects (Hasan \& Gould 1994, 1996, Hasan \& Lampitsi 1995, Hasan 1995), provide insight into the information needs, not only of senior mangers, but of enterprises as a whole. The convergence of a set of factors, including advances in technology, pressures of the economic climate and the changing structures of many organisations, suggests that the time is propitious to look at the wider picture of EIS, no longer "Executive" but "Enterprise" Information Systems. It is imperative to make use of innovative tools in order to provide effective (Enterprise) EIS to support Public Sector Organisations of the 1990s.

For the purpose of the thesis presented in this paper it is necessary to clearly distinguish between two sets of organisational systems that involve computerised technology: operational systems, that perform the business of the organisation, and IS, that provide information to assist with the management of the business and really do process "information". Only the latter will be called IS throughout this paper. That is not to say that there is a clear distinction between the two types of system and that there do not exist many systems that perform both functions. From their inception Executive IS have been systems designed to be pure IS and for that reason, as well as the fact that they have the attention of top management, Executive IS have been a catalyst in some organisations for a true IS to serve the whole enterprise.

\section{SPECIAL CHARACTERISTICS OF IS IN PUBLIC ORGANISATIONS}

Hasan and Gould (1994) have stated that Australian Federal and State Government Departments are shifting from the traditional "public service" non-profit orientation, to a market driven model and organisations in the public sector are consequently looking to adopt elements that have already been used in private sector organisations to support this approach. In an era of rapid change, this lag behind the private sector in IT innovations can sometimes be seen as an advantage, as much can learned from their experience. However to be immediately competitive, organisations in the public sector now need to make optimum use of applications such as Executive IS, as the climate is such that changing government regulatory requirements, with increased accountability, mean that information support for strategic planning becomes critical.

Public Sector organisations have at least two constraints that hinder Executive IS development. One of these is the cost and risk of such systems. As observed by Mohan et al (1990) many private companies do not consider it unreasonable to pay $\$ 2$ million for a top management support tool, whereas the fixed budget of most public organisations prohibits this.

The second constraint is the extra complexity of information in the public sector particularly in service areas such as health, education and welfare, which are recognised as "information intensive". As well as having to satisfy the customer or market, public organisations are in a position of having to satisfy governments to compete for public funds and to provide prescribed public services. This results in a complex set of policy issues, affected by the interaction of political, economic and social factors. There are many constraints and unknowns, with several parties involved in the decision making process. Many of the 
government imposed performance measures may conflict with the internal goals of the organisation.

Due to this extra complexity, IS in public sector organisations are difficult to design, build and maintain, particularly within a restricted budget. It is therefore critical to take advantage of any lessons learnt from the failure of previous Executive IS projects, mainly in the private sector, and to make use of any innovations that modern IT can offer.

\section{LESSONS LEARNT FROM EXECUTIVE IS}

The 1980s saw the growth of Executive IS. Following an extensive survey of Executive IS in large, mostly private companies, Watson et al (1991) provide a useful definition of Executive IS as computerised systems that "provide executives with easy access to internal and external information that is relevant to their critical success factors". Executive IS of the 1980s were characterised by their ability to extract, filter, compress and track critical data and allow it to be presented in a form suitable to the user. They were designed to be used directly by individual executives for strategic planning and control.

This description of Executive IS is not unlike the hopes that new computer applications have generated over the years for the ultimate IS for senior management. In the 60s and 70s it was predicted that the introduction of MIS would allow senior managers to supervise operations directly and would see the demise of Middle Managers. Now the term MIS is only used for systems at the tactical level of an organisation where reports are generated from data in operational systems. Database Management Systems (DBMS) with facilities for ad hoc queries, Decision Support Systems (DSS) and Expert or Knowledge Based Systems (KBS) were also prominent but senior executives did not readily adopt them, delegating their use to staff below them.

Many Executive IS of the 1980s were a great show piece for the organisation and were useful for some executives. However there was a high failure rate of such systems, quoted at as high as $70 \%$ (Murray 1992, Crockett 1992). Several of those that were successful have, in the 1990s, expanded to become indispensable Enterprise Information Systems, with a wide range of users throughout the organisation and with added functionality to support communication, data analysis as well as the ability to manage non-quantitative or "soft" information with textual search engines.

The approach presented in this paper is based on on-going research being carried out into the development and use of Executive IS in the Australian public sector (Hasan \& Gould 1994, 1996, Hasan \& Lampitsi 1995, Hasan 1995). In three of the organisations studied, the EIS has recently infiltrated lower levels of the organisation where the number of middle management users far exceeds the number of executive users, a phenomenon that in not uncommon (Watson \& Frolick 1993). The experience in these three organisations will be described and used to illustrate a number of concepts related to innovations in enterprise information systems. 


\section{THREE ENTERPRISE INFORMATION SYSTEMS}

Organisation One is a public utility serving a large widely dispersed population both rural and suburban. The appointment of a young, energetic, forward thinking Chief Executive Officer (CEO) in the early 1990s coincided with the start of an Executive IS project in which the new CEO took an immediate interest. The thrust of his new management was to initiate a processes of goal setting and identification of Key Performance Indicators (KPIs), beginning with the organisation's goals and working down to the goals of each business unit of the organisation. Under the direction of the CEO, the Executive IS project was linked to this goal setting process with the deliberate intention of providing information support for the KPIs of each business unit. After the successful implementation of the Executive IS to support the KPIs of the organisation as a whole, the EIS was given the new name of Business Information System (BIS) and has since become an integral part of the organisation. Each business unit is responsible for setting its own KPIs and for determining the information that it requires on the BIS. The BIS has an ongoing maintenance team responsible for changes and for new developments. From the outset, a strictly enforced directive from the CEO ensured that once information was available on the BIS this would be the only source of that information and all paper files destroyed. At first employees were not able to make hard copies of information from the BIS but this restriction was lifted once the BIS was fully established and managers now take pride in displaying the attractive graphical printouts of their unit's progress.

Organisation Two is a large government department in the service industry. An Executive IS was built in the early 1990 s purely for use by senior executives. It provided summaries of the statistical data typical of this industry and also soft data such as ministerial press releases, and other media reports. Users were required to pay for access to the system, a factor which effectively limited its use to department heads who controlled budgets. After several years of evolution and use, the Executive IS became well known as a success and used as demonstration to various community groups interested in Executive IS development. It was at these demonstrations that some lower level managers and professional staff of the organisation had their first real glimpse of the system and were impressed by the presentation of information that they too would find useful. There was consequently a demand for the system to be more widely available in the organisation. This has now eventuated, and with a substantial increase in the number of users the cost per user has dropped to a manageable level. There has been little change to the content of the system as the information it provides is all contained in public reports and is not confidential to senior managers.

Organisation Three is a public educational and research organisation the majority of whose staff are highly educated, computer literate professionals. Over the years the organisation's administration has built some formal MIS and even initiated an Executive IS project which, though not completed, did inspire the consolidation of organisational data into a data warehouse. The introduction of an organisation-wide computer network has seen a huge increase in the flow of useful information between members of the organisation using email and, more recently, internet facilities such as the World Wide Web. The organisation now recognises that this has become their most effective "information system", and is encouraging everyone to place information of value to others on the internal network. As a result, people 
now "click on their net browser" to access the data warehouse, to find out the state of their accounts, to look up internal telephone numbers and to view the results of the latest experiments. They use the same system to download the latest publications in their field from across the world. This system relies heavily on the willingness of a disjointed set of groups and individuals to set up and maintain items of interest, but it also gives the flexibility to handle all forms of hard and soft data and provides tools, such as search engines, to deal with the huge amounts of information that are produced. Within the organisation there is a committee which monitors the system, setting guidelines and providing user support.

While people at all levels of an organisation need the right information, which is up to date, accurate and in the right form, there is no single simple answer to this need. A variety of system and modes of operation may be appropriate for different organisations, under different circumstances, highlighting the importance of innovation in their design and development.

\section{INNOVATIVE WAYS OF CREATING ENTERPRISE IS}

It is difficult to train developers to be innovative, as innovation relies on the creativity, insight and flair of individuals. However for the development of innovative Enterprise Information Systems the following guidelines are proposed. It is essential for both designers and users to have the same appreciation of what is meant by the term information system. Together they should attempt to ascertain what are the basic requirements of an information system in the context of their organisation, recognising that this may not be a simple product but involve a wide variety of tools and methods.

An information system is a tool used by managers and others to enhance their performance by being better informed. As mentioned previously, it is helpful to distinguish information systems from operational systems which automate work practices. True IS are tools to support the work of managers involved in setting goals, making decision and monitoring the progress of the organisation towards its goals. However to design and develop systems, most computer programmers and systems analysts follow a traditional methodology based on the development of operational systems which automate well-structured tasks previously carried out by people. In such methodologies a detailed analysis of the problem leads to a comprehensive list of requirements which are then implemented in a system. This has worked with operational systems but over the years the same methodology has been used to develop IS such as MIS and DSS with mixed results. In most cases these systems have lacked the flexibility for use by senior managers.

The introduction of Executive IS in the 1980s marked a turning point; here were systems built specifically to provide information on an ad hoc basis for the support of managerial decision making. Executives actually used these systems. Indeed the current trend for these systems to be used by people through organisations, tells us that this type of product is what most people are looking for in an information system: flexibility, ease of use, a variety of attractive data presentation formats and the ability to interactive drill down through the maze of data. 
As the literature on the Executive IS of the 1980s has shown, building such a system for a particular organisation is not a simple matter of following a step by step methodology. Most authors of the time recommend an evolutionary prototyping development process so that the system capabilities can continually be adapted to meet changing user requirements. In this process the system begins as a small prototype which is regularly evaluated to give feedback which is used to modify the system. The prototype evolves into the "real" system which may continue to evolve via the same process. This obviates the need for a full list of system requirements to be gathered by the usual methods of analysing existing processes and interviewing users. These have always been found to be impractical when the users are senior managers. It also prepares management for a substantial commitment of resources over an extended period of time well after the system is introduced.

Though innovative in its time, the evolutionary prototyping methodology is now standard practice in the development of interactive systems where the interface design is of critical importance. A more comprehensive framework for EIS development has been proposed (Hasan \& Gould 1996) which gives more scope to innovation with the tools available in the 1990s. This framework introduces four stages which precede a final stage of evolutionary prototyping and from our observations greatly improve the chances of success. The framework was specifically developed for a public sector organisation where resources may be limited and information needs not well-defined as in private company with a set of products to sell and a clear profit motive.

Table 1 An outline of the 5 stage framework for EIS development:

\begin{tabular}{|l|l|l|}
\hline Stage & \multicolumn{1}{|c|}{ Outline } & \multicolumn{1}{c|}{ Comments and Examples } \\
\hline 1 & $\begin{array}{l}\text { Setting business goals, identifying } \\
\text { KPIs establishing broad information } \\
\text { needs and obtaining top management } \\
\text { support. }\end{array}$ & $\begin{array}{l}\text { The importance of this stage was } \\
\text { clearly demonstrated in all cases, } \\
\text { particularly Organisation One. }\end{array}$ \\
\hline 2 & $\begin{array}{l}\text { Data rationalisation, identification of } \\
\text { the legitimate sources of important } \\
\text { data sets and establishing uniformity } \\
\text { of key field formats. }\end{array}$ & $\begin{array}{l}\text { Poor data constructs were particularly } \\
\text { evident in Organisation Three which } \\
\text { expended a great deal of effort in a } \\
\text { Data Warehouse project }\end{array}$ \\
\hline 3 & $\begin{array}{l}\text { Exploratory prototype where one or } \\
\text { more supportive executive can } \\
\text { experiment with a simple IS quickly } \\
\text { set up with any tools the organisation } \\
\text { has at hand. }\end{array}$ & $\begin{array}{l}\text { This is particularly useful to enhance } \\
\text { communication between developers } \\
\text { and users to clarify the basic } \\
\text { requirements of the system }\end{array}$ \\
\hline 4 & $\begin{array}{l}\text { Implementation of the first version of } \\
\text { a real system }\end{array}$ & $\begin{array}{l}\text { Experienced system developers should } \\
\text { be given control at this stage to ensure } \\
\text { a quality product }\end{array}$ \\
\hline 5 & $\begin{array}{l}\text { Continued Evolutionary } \\
\text { Development and Use }\end{array}$ & $\begin{array}{l}\text { Processes are established to obtain feed } \\
\text { back from the users, to evaluate and } \\
\text { prioritise these, and to implement them }\end{array}$ \\
\hline
\end{tabular}


With a lessening in the distinction between Executive IS and Enterprise IS, this framework, devised from observations of many Executive IS projects, has the flexibility to guide a wide variety of Enterprise IS projects. Indeed many of the traditional categories of IS are breaking down making it harder to distinguish between them. Further more software systems, that are marketed as sole solutions to an organisations entire information needs, should not necessarily be considered solutions on their own, but useful building blocks of an integrated IS. Some examples of these are summarised in the following table:

Table 2 IT tools that can be used as components of an effective Enterprise IS

\begin{tabular}{|c|c|}
\hline Tool & Comments \\
\hline $\begin{array}{l}\text { Multi-dimensional Database } \\
\text { Management Systems } \\
\text { (MDDBMS) with On-Line } \\
\text { Analytic Processing (OLAP) }\end{array}$ & $\begin{array}{l}\text { Have been the basis of Executive IS in large profit } \\
\text { driven firms with a clearly defined product range but } \\
\text { now only one aspect of the information picture in more } \\
\text { diverse organisations. }\end{array}$ \\
\hline $\begin{array}{l}\text { Data-warehousing and Open } \\
\text { Systems }\end{array}$ & $\begin{array}{l}\text { The basis of a good IS but needs tools such as OLAP } \\
\text { and GUI interfaces to present useful information to } \\
\text { management }\end{array}$ \\
\hline Decision Support Systems & $\begin{array}{l}\text { Can be combined with traditional EIS to provide data } \\
\text { analysis and predictive facilities }\end{array}$ \\
\hline $\begin{array}{l}\text { Direct Manipulation with GUI } \\
\text { point and click interactive } \\
\text { systems }\end{array}$ & $\begin{array}{l}\text { Important in providing consistency and usability to IS. } \\
\text { Simply placing this type of interface onto existing } \\
\text { database systems may mean the difference to their } \\
\text { usefulness to mangers. }\end{array}$ \\
\hline $\begin{array}{l}\text { Object Oriented }(\mathrm{OO}) \text { systems } \\
\text { using reusable modules and } \\
\text { inheritance }\end{array}$ & $\begin{array}{l}\text { This technique is ideal for evolving systems. It enables } \\
\text { change and give end-users power to manipulate } \\
\text { systems on their own. }\end{array}$ \\
\hline $\begin{array}{l}\text { Artificial Intelligent and } \\
\text { Expert Systems. }\end{array}$ & $\begin{array}{l}\text { Expert systems have had limited success on their own } \\
\text { but applying knowledge-based techniques to intelligent } \\
\text { interfaces agents can revolutionise a user's ability to } \\
\text { handle large amounts of information }\end{array}$ \\
\hline $\begin{array}{l}\text { Internet Browsers and Text } \\
\text { Search Engines }\end{array}$ & $\begin{array}{l}\text { Can provide the flexibility to handle soft data and } \\
\text { extends the IS beyond the boundaries of the } \\
\text { organisation }\end{array}$ \\
\hline Multimedia Systems & $\begin{array}{l}\text { Extend the concept of information beyond the } \\
\text { traditional computer limitations of numbers and text, } \\
\text { matching more human-like means to transferring } \\
\text { information. }\end{array}$ \\
\hline Manual Processes & $\begin{array}{l}\text { In the push to make the best use of computerised IS } \\
\text { designers often overlook the possibility that the } \\
\text { optimum solution for some aspects of the system may } \\
\text { be carried out manually be organisational staff. }\end{array}$ \\
\hline
\end{tabular}




\section{CONCLUSION}

In public sector organisations information requirements are complex and resources are limited. This paper describes some of the methods and tools that may be used to provide an appropriate IS solution for an enterprise using available resources. . The framework referred to in this paper may give some guidance as to the methods which may be used. Likewise a selection of the various tools and techniques listed in the last table may be used together to develop an appropriate integrated system. However, Enterprise IS developers must be innovative in the use both of the methods and of the tools to produce the best, affordable information system for their organisation.

\section{REFERENCES}

Crockett, F. (1992) Revitalising Executive Information Systems, Sloan Management Review, Summer 1992, 39-47..

Hasan, H. and Gould, E. (1994) EIS in the Australian Public Sector, Journal of Decision Systems 3/4, 301-319.

Hasan, H. and Lampitsi, S. (1995) Executive Access to Information in Australian Public Organisations, Journal of Strategic Information Systems 4/2 1995.

Hasan, H. (1995) Organisational Issues and Implications of EIS, Proceedings of ACIS95 Perth 207-218.

Hasan, H. and Gould, E (1996) A Framework For EIS Development in The Public Sector to appear in the Proceedings of IRMA, Washington.

Kraemer, K.L., Danziger, J.N., Dunkle, D.E. and King, J.L. (1993) The Usefulness of Computer-Based Information to Public Managers, MIS Quarterly, June 1993, 129-148.

Mohan, L. Holstein, W. and Adams, R. (1990) EIS: It Can Work in the Public Sector MIS Quarterly December 1990, 435-448.

Murray, R. (1992) How to handle an EIS MIS July 1992, 30-39.

Watson, H., Rainer, R. \& Koh, C.E. (1991) Executive Information Systems: A Framework For Development and a Survey of Current Practices, MIS Quarterly, March 1991,13-30.

Watson, H. and Frolick, M. (1993) Determining the Information Requirements for an EIS, MIS Quarterly, September 1993, 255-268.

\section{BIOGRAPHY}

Helen Hasan currently holds a position as a senior lecturer in the Department of Business Systems at the University of Wollongong, NSW, Australia. Her career began with a first degree in Physics, followed by a Master of Science in Biophysics. An interest in computer programming led her to the emerging fields of Information Systems and Human Computer Interaction. She now teaches in these areas to both undergraduate and postgraduate students. Her research into the human aspects of Executive Information Systems has produced many publications and recognition throughout the country. 